\title{
Discordance between Lifestyle-Related Health Practices and Beliefs of People Living in Kuwait: A Community-Based Study
}

\author{
Suad Alfadhlia Sabriyah Al-Mazeedi ${ }^{b}$ Michael E. Bodner ${ }^{c} \quad$ Elizabeth Dean ${ }^{d}$ \\ Departments of a Medical Laboratory Sciences and ${ }^{b}$ Physical Therapy, Faculty of Allied Health Sciences, Kuwait \\ University, Kuwait, Kuwait; ' School of Human Kinetics, Trinity Western University, Langley, BC, and d Department of \\ Physical Therapy, Faculty of Medicine, University of British Columbia, Vancouver, BC, Canada
}

\section{Keywords}

Lifestyle beliefs - Lifestyle practices - Lifestyle health status . Kuwait $\cdot$ Healthy living $\cdot$ Noncommunicable disease risk reduction

\begin{abstract}
Objective: To examine the concordance between lifestyle practices and beliefs of people living in Kuwait, and between their lifestyle practices and established evidence-informed recommendations for health. Subjects and Methods: A cross-sectional interview questionnaire study was conducted using a convenience sample of 100 adults living in Kuwait (age range 19-75 years). The interview included sections on demographics, and lifestyle-related practices and beliefs related to smoking, diet/nutrition, physical activity/exercise, sleep, and stress. Diet/nutrition and physical activity/exercise benchmarks were based on international standards. Analyses included descriptive statistics and the $\chi^{2}$ test. $\boldsymbol{R e}$ sults: Beliefs about the importance of nutrition in lifestylerelated conditions were limited, and this was apparent in participants' dietary habits, e.g., low consumption of fruit/ vegetables and multigrains: $16(16 \%)$ and $9(9 \%)$ met the recommended guidelines, respectively. Ninety-nine (99\%) believed physical activity/exercise affects health overall, and 44 (44\%) exercised regularly. Of the sample of 100, 20 (20\%) ex-
\end{abstract}

ercised in accordance with evidence-based recommendations for maximal health. Compared with beliefs about other lifestyle-related behaviors/attributes, respondents believed nutrition contributed more than stress to heart disease, cancer, and stroke, and stress contributed more than nutrition to hypertension and diabetes. Conclusion: In this study, our findings showed a discrepancy between lifestyle-related practices and beliefs, and between each of these and evidence-based recommendations for maximal health, i.e., not smoking, several servings of fruit and vegetables and wholegrain foods daily, healthy weight, restorative sleep, and lowto-moderate stress levels.

(c) 2016 S. Karger AG, Basel

\section{Introduction}

The "Kuwait National Programme for Healthy Living: First 5-Year Plan (2013-2017)" has been a much anticipated document outlining a multisectorial strategy to curb the prevalence of lifestyle-related noncommunicable diseases (NCDs), especially obesity and type 2 diabe-

Elizabeth Dean was a visiting professor at the Department of Physical Therapy, Faculty of Allied Health Sciences, Kuwait University, Kuwait, at the time of this study.

\section{KARGER}

E-Mail karger@karger.com www.karger.com/mpp (c) 2016 S. Karger AG, Basel

Karger

This is an Open Access article licensed under the terms of the Creative Commons Attribution-NonCommercial 3.0 Unported license (CC BY-NC) (www.karger.com/OA-license), applicable to the online version of the article only. Distribution permitted for non-commercial purposes only.
Prof. Elizabeth Dean

Department of Physical Therapy, Faculty of Medicine

University of British Columbia, 2177 Wesbrook Mall

Vancouver, BC V6T 1 Z3 (Canada)

E-Mail elizabeth.dean@ubc.ca 
tes mellitus, in individuals residing in Kuwait [1]. The prevalence of these conditions is at critical levels and is contributing to significant social and economic burdens to the country [2]. Risk factors associated with these conditions (e.g., elevated levels of cholesterol, blood sugar, and blood pressure; and obesity) are no longer only afflictions of older adults but also of children and young adults $[3,4]$.

Lifestyle-related NCDs constitute a constellation of deadly conditions that are strongly associated with lifestyle choices and behaviors, yet are largely preventable [5]. These diseases include ischemic heart disease, hypertension, stroke, smoking-related conditions such as chronic obstructive lung disease, type 2 diabetes mellitus, obesity, and cancer. In addition to their associated foreboding of premature death, these diseases contribute to substantial disability and reduced quality of life, often over many years in a person's life. Multipronged strategies designed to control and prevent lifestyle-related NCDs are urgently needed in Kuwait comparable to other oil-rich countries in the Middle East [6].

The present study complements the Kuwait National Programme for Healthy Living [1] by identifying factors that may be particularly relevant to inform public health education, and health promotion practice and research in the state of Kuwait. Given no benchmark exists, the objective of this study was to examine the concordance of lifestyle-related practices and beliefs of Kuwait residents, and the concordance of their lifestyle-related practices with evidence-informed recommendations.

\section{Subjects and Methods}

The Kuwait University Health Sciences Centre Ethics Review Board approved this study and it conformed to the Declaration of Helsinki. A cross-sectional study based on a standardized interview questionnaire was conducted. Written informed consent was obtained from the participants. A sample of convenience of the people of Kuwait was used. To achieve a representative sample, residents were sampled from a range of public places, e.g., popular shopping areas, parks, and beaches in the Salmiya and Shuwaikh areas.

Adults over the age of 18 years, native or resident of Kuwait for at least 1 year, able to understand Arabic or English, and respond verbally to the questions posed by the interviewer met the inclusion criteria. The exclusion criteria were evidence of cognitive impairment and/or inability to communicate. One hundred individuals were eligible to participate. The sample of convenience consisted of 100 respondents.

\section{Interview Survey Questionnaire}

An interview questionnaire was constructed based on previous studies $[7,8]$ that included three sections: demographics; lifestyle- related health status, and practices related to smoking, diet and body composition, physical activity and exercise, sleep, and stress; and beliefs related to these lifestyle attributes and behaviors. In the diet and body composition section, the participants were asked to selfreport their weight classifications (i.e., underweight, healthy weight, and overweight), and these were compared to their body mass indices (BMIs) calculated from participants' self-reported weights and heights. This was included because of the epidemic of obesity in Kuwait. The interview was completed on average in 20-30 min.

To maximize the quality of the respondents' responses, the number of interviewers was limited to two, and it was ensured that they were comparably trained in administering the questionnaire and responding to questions. Further, we chose face-to-face data collection given cultural considerations and to limit the possibility of missing data. Also, confidentiality was emphasized to help ensure the accuracy and validity of responses.

Two female interviewers (S.A. and S.A.-M.) with bilingual proficiency in Arabic and English were trained to conduct the questionnaire in a standardized manner. Interviewers approached members of the community sequentially in each preestablished location. After a brief introduction into the study, each potential respondent was asked if he or she would like to participate and, if so, now or later. If the respondent agreed to be interviewed later, a time was arranged.

Reference Standards for Body Composition, Diet, and Physical Activity/Exercise

The World Health Organization (WHO) standards for body composition, specifically BMI, were used [9]. Nutrition guidelines for the Gulf region supported by the WHO Eastern Mediterranean Region were adopted [10]. To illustrate serving sizes, pictures from the Canadian food guidelines [11] were used. These guidelines are not dissimilar to the Gulf guidelines [10,11]. Evidence-informed regular physical activity and exercise levels for optimal health (i.e., moderate to vigorous-intense activity or exercise for 30-60 min, 3-5 days a week, i.e., $150 \mathrm{~min}$ a week) were based on the recommendations of the Harvard Medical School Special Health Report on exercise [12] and other established authorities [13].

\section{Statistical Analysis}

The data were analyzed using SPSSX software version 17.0 (Chicago, IL, USA). Descriptive statistics were used to summarize and analyze the demographic data. Frequencies and percentages were used to analyze and compare responses to questions about lifestyle health beliefs and practices. $\chi^{2}$ tests were used to assess relationships between nutritional practices and established nutrition guidelines for fruit/vegetables, grains, meat/fish, and dairy consumption. For this descriptive study, we did not stratify the data based on Kuwaiti and non-Kuwaiti, nor gender. a was set at 0.01 to adjust for multiple test comparisons.

\section{Results}

\section{Sample Description and Representativeness}

The demographics of the participants are given in Table 1 . The mean age of the participants was $34.2 \pm 11$ years. 
Table 1. Participant demographic information for Kuwait residents $(n=100)$

$n(\%)$

\begin{tabular}{lc} 
Education $(n=90)$ & \\
No formal schooling & $5(5.5)$ \\
Elementary/junior high school & $9(10.0)$ \\
High school/diploma/junior college & $36(40.0)$ \\
Bachelor's degree/vocational & $32(35.6)$ \\
Graduate degree/PhD & $8(8.9)$ \\
\hline
\end{tabular}

Employment: professions and occupations $(n=100)$

Administration/management 13 (13)

Customer service $4(4)$

Sales/service sector $18(18)$

Business/banking 1 (1)

Professional $28(28)$

Retired/nonspecified $19(19)$

Unemployed

$17(17)$

\begin{tabular}{lc}
\hline Salary $(n=99)$ & \\
Salary/month & $18(18.2)$ \\
None & $56(56.6)$ \\
KWD $<600($ USD 2,100) & $22(22.2)$ \\
KWD 600-900 (USD 2,100-3,150) & $3(3.0)$ \\
KWD $>900($ USD 3,150) &
\end{tabular}

Marital status $(n=100)$

Married $61(61)$

Single $35(35)$

Divorced $3(3)$

Widowed 1 (1)

Country of origin $(n=100)$

Kuwait $54(54)$

Other Middle Eastern countries $25(25)$

India/Bangladesh $14(14)$

Other 7 (7)

Of the 100 respondents, 42 (42\%) reported being in excellent health, 55 (55\%) in somewhat good health, and $72(72 \%)$ reported they could climb two flights of stairs without difficulty. Self-reported physician-diagnosed conditions that respondents reported included: obesity: 28 (28\%); osteoarthritis: 15 (15\%); anemia: 10 (10\%); irritable bowel syndrome: 13 (13\%); and high blood pressure: $10(10 \%)$.

\section{Smoking}

Twenty-five (25\%) respondents reported being current smokers. Of these, $10(40 \%)$ smoked a pack or more of cigarettes daily. Of the 75 respondents who responded to the question about second-hand smoke exposure, 29 (38.7\%) reported such exposure.
With respect to smoking beliefs, all respondents believed that smoking contributed to lifestyle-related NCDs. They believed that this association was less strong for stroke: 69 (69\%); hypertension: 64 (64\%); type 2 diabetes mellitus: 22 (22\%); and osteoporosis: $16(16 \%)$, compared with lung disease: 96 (96\%), cancer: 91 (91\%); and heart disease: 89 (89\%).

All respondents believed that smoking was harmful to health. Of the 98 who responded to the question "what level of smoking was harmful for health", 13 (13.3\%) believed that this level was more than 1 pack/ day; for 4 (4.1\%), it was between 0.5 and 1 pack/day; and for $81(81.6 \%)$ the critical amount was less than 0.5 pack/day. Of the 100 respondents, 85 (85\%) believed that smoking fewer cigarettes was more beneficial than smoking more; however, based on their beliefs, they appeared less knowledgeable about the need for not smoking at all. Although 89-96 (89-96\%) of participants believed smoking contributed a great deal to heart disease, lung disease, and cancer, only 64 and 69 (64 and 69\%) believed this was true for hypertension and stroke, respectively.

\section{Diet and Nutrition}

Of 90 participants who responded to questions about the perceived weight category and their self-reported heights and weights, 39 (43\%) respondents were in the healthy BMI range: 18.5-24.9; 7 (8\%), however, perceived they were underweight, and 7 (8\%) they were overweight. Of the 49 (54\%) who were calculated to be overweight, 13 (14\%) perceived themselves to be of a healthy weight.

Overall, 61 (67\%) respondents were accurate with respect to self-reported weight classification based on BMI, and the remaining 29 (33\%) were not. Of the 29 respondents, $8(8.8 \%)$ reported being underweight when they were either healthy weight or overweight/obese, 13 $(14.3 \%)$ reported being of healthy weight when they were overweight/obese, 7 (7.7\%) reported being overweight/ obese when they were of healthy weight, and 2 (2.2\%) reported they were of healthy weight when they were actually underweight.

Ninety-nine (99\%) participants believed that what people eat affects their health. Of several listed common lifestyle-related NCDs, 74 (74\%) respondents believed obesity had the greatest association with diet, followed by type 2 diabetes $(64 ; 64 \%)$, heart disease $(51 ; 51 \%)$, and hypertension (49; 49\%).

The daily number of servings of fruit/vegetables, grains, dairy, and meat products consumed by the par- 
Table 2. Participants' profiles of self-reported nutrition practices $(n=100)$

\begin{tabular}{cc}
\hline $\begin{array}{l}\text { Self-reported number of servings of } \\
\text { selected food groups }\end{array}$ & $n(\%)$ \\
\hline Fruit/vegetables & \\
0 & $9(9)$ \\
$1-3$ & $54(54)$ \\
$4-6$ & $27(27)$ \\
$\geq 7$ & $10(10)$ \\
Grains & $1(1)$ \\
0 & $33(33)$ \\
$1-3$ & $45(45)$ \\
$4-6$ & $21(21)$ \\
$\geq 7$ & \\
Dairy & $15(15)$ \\
0 & $25(25)$ \\
1 & $25(25)$ \\
2 & $16(16)$ \\
3 & $9(9)$ \\
$\geq 4$ & $6(6)$ \\
Meat & $16(16)$ \\
0 & $41(41)$ \\
1 & $19(19)$ \\
2 & $18(18)$ \\
3 &
\end{tabular}

Based on frequency of daily servings $[10,11]$ for fruit/vegetables, grains, dairy, meat products (meat, fish, and poultry).

Table 3. Congruence of participants' beliefs regarding required daily servings of fruits/vegetables, grains, dairy products, and meat recommended for optimal health $[10,11]$

\begin{tabular}{lc}
\hline Food type & $n(\%)$ \\
\hline Fruits/vegetables & $16(16)$ \\
Grains & $9(9)$ \\
Milk/dairy & $33(33)$ \\
Meat & $25(25)$ \\
\hline
\end{tabular}

ticipants are shown in Table 2. With respect to beliefs about the recommended number of daily servings of various food groups for a balanced diet, 16 (16\%) respondents' beliefs were consistent with the recommended daily servings of fruit and vegetables, 9 (9\%) for servings of grains; 33 (33\%) for dairy products, and 25 (25\%) for meat (Table 3). Overall, the number of servings was believed to be lower than recommended for all food catego- ries except for meat and fish, which were consumed in higher quantities than recommended.

A comparison of these dietary practices with respondents' nutritional beliefs showed significant differences for grains $\left(\chi_{1,100}^{2}=10.73, p<0.01\right)$, and for meat and fish $\left(\chi_{1,100}^{2}=7.34, p<0.01\right)$. No differences between their practices and beliefs were observed, however, for vegetables and fruit and milk/dairy products $(p>0.01)$.

\section{Physical Activity and Exercise}

Ninety-eight participants (98\%) believed that a person's physical activity and exercise levels affect health. Of several listed common lifestyle-related NCDs, 85 respondents $(85 \%)$ believed diabetes and obesity had the greatest association with physical inactivity, 79 (79\%) with heart disease (79\%), 79 with osteoporosis (79\%), and 77 with cancer (77\%). Hypertension was believed to be less associated with physical inactivity (59\%), whereas stroke was believed to be somewhat more associated (70\%). With respect to the type and frequency of exercise that was optimal for health, of 98 respondents, 54 (55\%) believed daily aerobic exercise was needed, and 26 (27\%) respondents believed aerobic exercise 2-3 times per week is required.

All participants $(n=100)$ responded to the questions about their physical activity/exercise levels, with 44 (44\%) indicating that they dedicated time for regular physical activity. Of these, however, only 20 (20\%) reported exercising at the evidence-based level of type, intensity, duration, and frequency consistent with optimal health.

\section{Sleep}

Of the total 100 respondents who answered the sleep questions, 60 (60\%) participants slept between 6 and $8 \mathrm{~h}$ nightly, and $25(25 \%)$ were below and $13(13 \%)$ above this range. Fifty-five (55\%) respondents reported they did not sleep well (i.e., were not restored on awaking in the morning).

Stress

All respondents believed chronic psychological stress has a negative effect on health. Of the 100 respondents, 47 (47\%) reported moderate stress, 31 (31\%) high stress, and $22(22 \%)$ low stress. With respect to several listed NCDs, 81 respondents believed stress has a major association with hypertension (81\%), 78 with stroke (78\%), and 72 with heart disease (72\%); and less association with obesity $(36 \%)$, cancer (35\%), and diabetes (20\%). 


\section{Discussion}

In this study, beliefs about the role of nutrition in lifestyle-related conditions were limited, and this was apparent in participants' dietary deficits, such as low consumption of fruit/vegetables and multigrains. The majority of respondents believed physical activity/exercise affected health overall (99\%); $44 \%$ exercised regularly and $20 \%$ exercised in accordance with evidence-based recommendations for maximal health. Compared with beliefs about other lifestyle behaviors/attributes, respondents believed nutrition contributed more than stress to heart disease, cancer, and stroke; and stress contributed more than nutrition to hypertension and diabetes.

Despite the fact that smoking is the leading cause of preventable death. Guidelines for optimal health recommend no amount of smoking is consistent with good health [14]. The prevalence of tobacco smoking is high in Kuwait, especially among men; smoking shisha is also culturally acceptable [15]. The degree to which the relatively low smoking rates in our sample could be explained by smoking alternatives to tobacco could not be established. With respect to beliefs about the deleterious effects of smoking on health, there was no general understanding that even a minimal amount of smoking is harmful.

The greatest disparity between lifestyle-related practices and beliefs of the respondents' was that for diet/nutrition and for physical activity/exercise versus other lifestyle behaviors/attributes (i.e., smoking, sleep, and stress), and lifestyle-related practices related to these, and evidence-based nutrition guidelines and recommendations.

Respondents' belief that a lower consumption of fruit, vegetables, and grains than that recommended for maximal health was optimal, was congruent with their low consumption of these essential food groups. This finding confirmed those of Zaghloul et al. [16]. Thus, health education aimed at both nutritional beliefs through increased knowledge and practice is needed. Healthy nutrition has to be targeted at families as well as children given the reports of rising prevalence rates of overweight and obesity among children $[17,18]$ and impaired glucose regulation in young adults [4].

The fact that only $20 \%$ of the entire sample undertook exercise at a level that was commensurate with maximal health benefit is consistent with data from the Kuwait Health Survey showing that three quarters of respondents were inactive consistent with the recommended guidelines of $150 \mathrm{~min}$ of exercise at moderate to vigorous intensity weekly $[12,13]$.
Inactivity of the people of Kuwait may be explained by a number of reasons. The people of Kuwait are at risk given their reliance on driving due to a range of environmental and societal factors, including minimal public transportation. Prolonged sitting is an independent risk factor for cardiometabolic diseases [19]. Thus, even if a person engages in regular physical activity, he or she may jeopardize health with prolonged periods of sitting. In addition, recent Canadian data show a strong association between driving and lack of physical activity [20]. Driving travel time has also been associated with increased body weight, a risk factor for type 2 diabetes mellitus [21].

Suboptimal sleep and moderate stress was reported by our respondents. Sleep deprivation has been associated with several NCDs $[22,23]$, thus there is justification for the assessment of the sleep quality and quantity of the people of Kuwait, and intervention in the form of sleep hygiene strategies as needed. Unabated chronic stress including the accumulation of daily hassles has been associated with NCDs and impaired sleep, which further impact physical, cognitive, and mental well-being [24].

The respondents to our questionnaire showed lifestyle-related practices as well as beliefs that were inconsistent with evidence-based recommendations for maximal health. These trends may be explained by a number of factors. First, Kuwait is following the path of western countries in terms of prevalence of lifestyle-related NCDs as it grows economically [6]. Second, previous work had shown that people in Kuwait tend to be overweight, and, perhaps because of this, do not engage in recommended physical activity or are unaware of nutritional guidelines [25]. The investigators explained their findings based on cultural factors. Given the effectiveness of the public policy regarding smoking in Kuwait [26] and other countries, and considerations forthe built-in environment such that "the healthy choice is the easy choice", such public policy solutions to the crisis of lifestyle-related NCDs in Kuwait generally warrant greater attention.

Based on our findings, knowledge about health beliefs and practices of a population could inform the design of health education campaigns and, in turn, augment people's health status. Extension studies that examine cultural, religious, and traditional practices are indicated as these are strong determinants of smoking practices, diet, activity, sleep, and stress. Aligning health education with culture and traditions as well as religion has been advocated by the WHO for many years [27]. This remains a 
powerful vehicle for health communication as has recently been demonstrated in a culturally adapted health education program for Saudi women at risk of type 2 diabetes mellitus [28]. In turn, such knowledge could enable health authorities in Kuwait to be proactive in maximizing the health of its population [29]. Our findings provide a basis for further studies to explore concordance of lifestyle practices and beliefs, and guidelines for lifestyle behavior change by targeting knowledge and beliefs as well as practices. Future studies including larger cohorts are needed to explore potential gender differences or differences between Kuwaiti and non-Kuwaiti respondents.

As in other questionnaire surveys, the responses to the items in our questionnaire depended upon the respondents' self-reports which are inherently challenging to validate. Self-reported health status, however, has been reported to have acceptable reliability and validity [30].

\section{Conclusion}

In this study, our findings showed a discrepancy between lifestyle-related practices and beliefs, and between each of these and evidence-based recommendations for maximal health, i.e., not smoking; several servings of fruit and vegetables and whole-grain foods daily; healthy weight; restorative sleep; and low-to-moderate stress levels. These findings could support the need for public health education in Kuwait consistent with the Kuwait National Program for health promotion and NCD risk reduction. Such education, however, could be targeted at lifestyle-related knowledge and beliefs of Kuwait's residents as well as practices to reduce the gap between them and, further, to align lifestyle-related practices and beliefs with scientific evidence for healthy living practices. Our findings have provided the basis for future studies aimed at reducing the high prevalence of lifestyle-related NCDs in Kuwait and maximize people's health through attention to lifestyle-related behaviors as well as beliefs.

\section{References}

1 Behbehani K: Kuwait National Programme for Healthy Living: first 5-year plan (20132017). Med Princ Pract 2014;23(suppl 1):3242.

2 World Health Organization: Kuwait Health system Profile 2006. http://gis.emro.who.int/ HealthSystemObservatory/PDF/Kuwait/ Full\%20Profile.pdf.

3 Alattar A, Al-Majed H, Almuaili T, et al: Prevalence of impaired glucose regulation in asymptomatic Kuwaiti young adults. Med Princ Pract 2012;21:51-55.

4 Shah NM, Behbehani J, Shah MA: Prevalence and correlates of major chronic illnesses among older Kuwaiti nationals in two governorates. Med Princ Pract 2010;19:105-112.

5 World Health Organization: Global Action Plan for the Prevention and Control of Noncommunicable Diseases 2013-2020. Geneva, WHO, 2013, http://apps.who.int/iris/bitstre am/10665/94384/1/9789241506236_eng. pdf?ua $=1$.

6 Dean E: The crisis of lifestyle conditions in the Middle East with special attention to Kuwait: an unequivocal evidence-based call to action. Kuwait Med J 2008;40:184-190.

7 Rodrigues G, Jongbloed L, Li Z, et al: Ischaemic heart disease-related knowledge, behaviours and beliefs of IndoCanadians and EuroCanadians: implications for physical therapists. Physiother Can 2014;66:208-217.
8 Wong WP, Yeung M, Loh S, et al: Stroke-related knowledge, lifestyle behaviours and health beliefs in Singaporean Chinese: implications for health education. Health Educ J 2013;72:386-397.

9 World Health Organization: Global Strategy on Diet, Physical Activity and Health. Geneva, WHO, 2004, http://www.who.int/dietphysicalactivity/strategy/eb11344/strategy_ english_web.pdf.

10 World Health Organization: Promoting a Healthy Diet for the WHO Eastern Mediterranean Region: User-Friendly Guide. Geneva, WHO, 2012. http://applications.emro.who. int/dsaf/emropub_2011_1274.pdf.

11 Health Canada. 2015. Eating Well with Canada's Food Guide. Ottawa, Health Canada, 2015, http://www.has.uwo.ca/hospitality/nutrition/pdf/foodguide.pdf.

12 Hartley LH, Lee I-M (eds): Starting to Exercise. A Harvard Medical School Special Health Report. Boston, Harvard Health Publications, 2015, www.health.harvard.edu (accessed May 16, 2016).

13 Garber CE, Blissmer B, Deschenes MR, et al: Quantity and quality of exercise for developing and maintaining cardiorespiratory, musculoskeletal, and neuromotor fitness in apparently healthy adults: guidance for prescribing exercise. American College of Sports Medicine position stand. Med Sci Sports Exerc 2011;43:1334-1359.
14 McCullough ML, Patel AV, Kushi LH, et al: Following cancer prevention guidelines reduces risk of cancer, cardiovascular disease, and all-cause mortality. Cancer Epidemiol Biomarkers Prev 2011;20:1089-1097.

15 Husain H, Al-Fadhli F, Al-Olaimi F, et al: Is smoking shisha safer than cigarettes: comparison of health effects of shisha and cigarette smoking among young adults in Kuwait. Med Princ Pract 2016;25:117-122.

16 Zaghloul S, Waslien C, Al Somaie M, et al: Low adherence of Kuwaiti adults to fruit and vegetable dietary guidelines. East Mediterr Health J 2012;18:461-467.

17 Al-Refaee FA, Al-Qattan SA, Jaber SM, et al The rising tide of overweight among Kuwaiti children: study from Al-Adan Hospital, $\mathrm{Ku}$ wait. Med Princ Pract 2013;22:600-602.

18 Moussa MAA, Shaltout AA, Al-Sheik N: Prevalence of obesity among 6- to 13-year-old Kuwaiti children. Med Princ Pract 1999;8: 277-280.

19 Thorp AA, Healy GN, Owen N, et al: Deleterious associations of sitting time and television viewing time with cardiometabolic risk biomarkers: Australian Diabetes, Obesity and Lifestyle (AusDiab) study 2004-2005. Diabetes Care 2010;33:327-334.

20 Swanson KC, McCormack GR: The relations between driving behavior, physical activity and weight status among Canadian adults. J Phys Act Health 2012;9:352-359. 
21 McCormack GR, Virk JS: Driving towards obesity: a systematic literature review on the association between motor vehicle travel time and distance and weight status in adults. Prev Med 2014:66:49-55.

22 Coren S: Sleep health and its assessment and management in physical therapy practice: the evidence. Physiother Theory Pract 2009;25: 442-452.

23 Epstein L (ed): Improving Sleep: A Guide to a Good Night's Rest. A Harvard Medical School Special Health Report. Boston, Harvard Health Publications, 2015, www.health.harvard.edu (accessed May 16, 2016).
24 Benson H, Casey A (eds): Stress Management; Approaches for Preventing and Reducing Stress. A Harvard Medical School Special Health Report. Boston, Harvard Health Publications, 2013, www.health.harvard.edu (accessed May 16, 2016).

25 Serour M, Alqhenaei H, Al-Saqabi S, et al: Cultural factors and patients' adherence to lifestyle measures. Br J Gen Pract 2007;57: 291-295.

26 Tobacco News. Country of Kuwait. Smoking Bans and Policies. http://archive.tobacco.org/ articles/country/kuwait/ (accessed May 16, 2016).
27 Al Khayat MH: The Right Path to Health. Health Education through Religion. Health. An Islamic Perspective. Geneva, World Health Organization, Regional Office for the Eastern Mediterranean, 1997, http://applications.emro.who.int/dsaf/dsa113.pdf.

28 Al-Bannay H, Jarus T, Jongbloed L, et al: Effects of a type 2 diabetes education programme culturally tailored to Saudi women's needs: a pilot study. Saudi Med J 2015;36:869873.

29 White F: The imperative of public health education: a global perspective. Med Princ Pract 2013;22:515-529.

30 Bombak AE: Self-rated health and public health: a critical perspective. Front Pub Health 2013;1:15. 